\title{
Treatability of Biodiesel Wastewaters By Using KMnO4 And KMn04/03 Processes And Kinetic Analysis
}

PInar N. TANATTI ( $\nabla$ ptanatti@subu.edu.tr)

Sakarya University of Applied Sciences https://orcid.org/0000-0002-2904-7334

\section{Research Article}

Keywords: Biodiesel wastewater, KMnO4 oxidation, KMnO4/03 oxidation

Posted Date: August 24th, 2021

DOl: https://doi.org/10.21203/rs.3.rs-739466/v1

License: (c) (1) This work is licensed under a Creative Commons Attribution 4.0 International License.

Read Full License 


\title{
Treatability of biodiesel wastewaters by using $\mathrm{KMnO}_{4}$ and $\mathrm{KMnO}_{4} / \mathrm{O}_{3}$ processes and kinetic analysis
}

\author{
N. Pinar TANATTI \\ 1) Department of Environmental Protection Technologies, Sakarya University of \\ Applied Sciences, Turkey, 54100 Sakarya-TURKEY
}

Corresponding author: N. P1nar TANATTI

E-mail address : : ptanatti@subu.edu.tr

Adress for all authors : Sakarya University of Applied Sciences, Department of Environmental Protection Technologies, 54100 Sakarya- TURKEY

Tel: +902642957356

Fax: +902642955601

\begin{abstract}
The purpose of this study is to investigate the treatability of electrocoagulated biodiesel wastewater $(\mathrm{ECBD})$ by potassium permanganate $\left(\mathrm{KMnO}_{4}\right)$ and potassium permanganate/ozone $\left(\mathrm{KMnO}_{4} / \mathrm{O}_{3}\right)$ processes. The ECBD removal efficiencies of both combined method and $\mathrm{KMnO}_{4}$ methods were compared and the $\mathrm{KMnO}_{4} / \mathrm{O}_{3}$ process gave better results than the $\mathrm{KMnO}_{4}$ process. For the ECBD removal efficiencies, the experimental parameters including $\mathrm{pH}$, potassium permanganate dose, ozone dose and reaction time parameters were optimized by changing the one parameter at a time. As a result of $6 \mathrm{~h}$ of $\mathrm{KMnO}_{4}$ oxidation, $91.74 \%$ of $\mathrm{COD}$ and $95.93 \%$ of $\mathrm{MeOH}$ removal
\end{abstract}


was achieved under the optimum conditions ( $\mathrm{pH} 2,5 \mathrm{~g} / \mathrm{L} \mathrm{KMnO}_{4}$ dose). However, under optimum conditions $\left(\mathrm{pH} \mathrm{13,2}\right.$ g/L $\mathrm{KMnO}_{4}$ dose, $3000 \mathrm{mg} / \mathrm{L} \mathrm{O} 3$ dose, $6 \mathrm{~h}$ reaction time), the $\mathrm{COD}$ and $\mathrm{MeOH}$ removal efficiencies have been obtained for $\mathrm{KMnO}_{4} / \mathrm{O}_{3}$ as $97.79 \%$ and $98.30 \%$, respectively. The second order kinetic model has been found to be the most suitable model for both processes and the regression coefficients $\left(\mathrm{R}^{2}\right)$ has been found as 0.999 and 0.999 for $\mathrm{KMnO}_{4}$ and $\mathrm{KMnO}_{4} / \mathrm{O}_{3}$, respectively. The reaction rate constants $(\mathrm{k})$ have been also calculated as $6 \times 10^{-5}$ L/mg.min and $1.63 \times 10^{-4} \mathrm{~L} / \mathrm{mg}$.min for $\mathrm{COD}$ and $\mathrm{MeOH}$ in $\mathrm{KMnO}_{4}$ oxidation, respectively. Furthermore, the reaction rate constants $(\mathrm{k})$ have been also calculated as $6 \times 10^{-5} \mathrm{~L} / \mathrm{mg}$.min and $1.6 \times 10^{-4} \mathrm{~L} / \mathrm{mg}$.min for $\mathrm{COD}$ and $\mathrm{MeOH}$ in $\mathrm{KMnO}_{4} / \mathrm{O}_{3}$ oxidation, respectively.

Keywords: Biodiesel wastewater, $\mathrm{KMnO}_{4}$ oxidation, $\mathrm{KMnO}_{4} / \mathrm{O}_{3}$ oxidation

\section{Introduction}

Increase in oil prices, fossil fuel depletion and the environmental problems, encourage the development of renewable fuels (Patino et al. 2018). Biodiesel has a great interest in the world as renewable and environmentally friendly fuel energy derived from biomass (Chi et al. 2018).

Generally, the biodiesel production process is the transformation of triglycerides into fatty acid methyl ester by using the transesterification process in the presence of alcohol and catalyst (Veljkovic et al. 2014). The impurities of produced biodiesel are removed with a large amount of water (Mohana et al. 2011). As a result of the washing process, large quantities of wastewater containing soap, catalyst, alcohol, free glycerol and free fatty acids (FFA) occurs (Rattanapan et al. 2011; Atadashi et al. 2011; Berrios and Skelton 2008). Generated wastewater has a high organic load, pungent odour and milky coloured (Veljkovic et al. 2014). Due to the high levels of chemical oxygen demand, biological oxygen demand, oil, suspended solid matters and dissolved solids, treatment of biodiesel wastewater is too hard.

In literature for Biodiesel wastewater treatment, various physical and chemical treatment methods studied, such as membrane filtration (Mozaffarikhah et al. 2017), adsorption (Pitakpoolsil and Hunsom 2014), acidification-coagulation (Rattanapan et al. 2011), coagulation-flocculation (Daud et al. 2015, Daud et al. 2018), 
electrocoagulation (Ngamlerdpokin et al. 2011; Tanatt1 et al. 2018; Ahmadi 2013; Srirangsan et al. 2009), electroflotation-electrooxidation (Romero et al. 2013; Jaruwat et al. 2010) and solvent extraction (Tanatt1 et al. 2018). Although the biological treatment of biodiesel wastewater is quite difficult due to its high pollution load, aerobic (Suehara et al. 2005) and anaerobic treatment (Siles et al. 2010; Nishio et al. 2007) have also been studied.

Ozone treatment of biodiesel wastewater has been examined before (Tanatt1 et al. 2019), but the ozone and permanganate oxidation has not been investigated in literatüre. Permanganate used as a strong oxidant $\left(\mathrm{E}^{0}=1.51 \mathrm{~V}\right)$ through the high reduction potential (Zhong ve Zhang 2019). In neutral, alkaline and acidic environments, permanganate ion is an important oxidizing agent. And especially in acidic medium, widely used for oxidation of organic and inorganic compounds (Althagafi and Fawzy 2016). In addition, permanganate is inexpensive, relatively stable, easy to use, and a highly effective oxidizer over a wide $\mathrm{pH}$ range (Song et al. 2019). Also, permanganate commonly used in wastewater treatment, micropollutants reduction and drinking water treatment as a green oxidant (Rodriguez et al. 2007; Zhang et al. 2014).

Permanganate is an effective oxidant for some chemicals and drugs, existing in wastewaters such as triclosan (Chen et al. 2016; Jiang et al. 2009), sulfamethoxazole (Gong and Chu 2018), bisphenol A (Zhang et al. 2013), sulfadiazine (Yang et al. 2018), chlorophene (Xu et al. 2018) and tetrabromobisphenol A (Pang et al. 2014).

Another strong oxidant used in this study is ozone $\left(\mathrm{E}^{0}=2.07 \mathrm{~V}\right)$ (Yang et al. 2017). In the oxidation of organic and inorganic compounds with ozone, reactions occur either directly as molecular ozone or indirectly with hydroxy radicals formed by the decomposition of ozone (Nawrocki and Kasprzyk-Hordern 2010; Li et al. 2018). Ozone oxidation mechanism takes place depending on $\mathrm{pH}$. While ozone reacts directly with organic substances under acidic conditions, at high $\mathrm{pH}(\mathrm{pH}>7)$ performs indirect oxidation reactions and rapidly generates hydroxyl radicals and other species (Patzior et al. 2017).

In this project, the treatments of pre-treated raw biodiesel wastewater (with electrocoagulation) were investigated with the oxidation of with potassium permanganate $\left(\mathrm{KMnO}_{4}\right)$ and potassium permanganate $\left(\mathrm{KMnO}_{4} / \mathrm{O}_{3}\right)$. In $\mathrm{KMnO}_{4}$ 
oxidation process to investigate the removal efficiencies of chemical oxygen demand (COD) and methanol $(\mathrm{MeOH})$ and in electrocoagulated biodiesel wastewater (ECBD) $\mathrm{pH}, \mathrm{KMnO}_{4}$ dose and reaction time parameters examined. At $\mathrm{KMnO}_{4} / \mathrm{O}_{3}$ oxidation process $\mathrm{pH}, \mathrm{KMnO}_{4}$ dose, $\mathrm{O}_{3}$ dose and reaction time parameters were studied. Depending on time studies and obtained optimum conditions, $\mathrm{KMnO}_{4}$ and $\mathrm{KMnO}_{4} / \mathrm{O}_{3}$ oxidation processes were examined in terms of kinetics for ECBD wastewater.

\section{Materials and methods}

\subsection{Characterization of biodiesel wastewater}

Biodiesel wastewater was produced in the Environmental Engineering Laboratory of Sakarya University with the method given at Tanatt1 et al. 2018. The produced raw biodiesel wastewater was pre-treated with electrocoagulation (Tanatt1 et al. 2018) and got ready for oxidation studies. In electrocoagulation (EC) process has been worked as initial $\mathrm{pH} 6$, conductivity $(\mathrm{NaCl}) 1 \mathrm{~g} / \mathrm{L}$, current density $0.3226 \mathrm{~mA} / \mathrm{cm}^{2}$ and optimum electrolysis time of 1 minute. Although all fatty acid methyl esters are removed in the EC method, $\mathrm{COD}$ and $\mathrm{MeOH}$ values are not appropriate for discharge to the receiving environment. Therefore, after electrocoagulation ECBD needs an advanced treatment method as $\mathrm{KMnO}_{4}$ and $\mathrm{KMnO}_{4} / \mathrm{O}_{3}$ oxidation. Characterization of ECBD wastewater is shown in Table 1.

\subsection{Chemical analysis}

COD analyses were measured according to the Standard Methods for Control of Water and Wastewater, method $5220 \mathrm{D}, 23^{\text {rd }}$ edition (APHA 2017). $\mathrm{pH}$ adjustments were made with $\mathrm{NaOH}$ and $\mathrm{H}_{2} \mathrm{SO}_{4}$ solutions.

$\mathrm{MeOH}$ concentrations were measured spectrometrically with SHIMADZU UV/Vis 1700 model spectrophotometer device. $10 \%(\mathrm{~m} / \mathrm{v})$ sodium nitroprussite, $10 \%(\mathrm{~m} / \mathrm{v})$ potassium ferricyanate and $5 \%(\mathrm{~m} / \mathrm{v})$ sodium hydroxide solutions were used as reagents in the analysis (Zhan et al. 2010). For the preparation of the chromogenic reagent (SNP), first the reagent solutions are combined and then doubled with pure water at volumetric flask. For methanol analysis, $6 \mathrm{~mL}$ of SNP is added to $1 \mathrm{~mL}$ of 
sample and shaken for $1 \mathrm{~min}$. After waiting 45 minutes at room temperature and absorbance value is measured in the spectrophotometer at $481 \mathrm{~nm}$ wavelength.

\subsection{Reactor Design}

The reactor design of the $\mathrm{KMnO}_{4} / \mathrm{O}_{3}$ process used in the study is shown in Figure 1. As shown in Figure 1, the $\mathrm{KMnO}_{4} / \mathrm{O}_{3}$ process has consisted of an ozone generator with a capacity of $0,3 \mathrm{~g} / \mathrm{h}$, a magnetic stirrer and a $300 \mathrm{ml}$ glass reactor.

\section{Results and Discussion}

\subsection{Effect of $\mathrm{pH}$ in $\mathrm{KMnO}_{4}$ and $\mathrm{KMnO}_{4} / \mathrm{O}_{3}$ processes}

In $\mathrm{KMnO}_{4}$ oxidation, $\mathrm{pH}$ is considered as one of the most important parameter to remove organic pollutants (Yang et al. 2018). Permanganate has been proven by many studies to perform an electron exchange of five electrons under acidic conditions, three electrons under neutral mild alkaline conditions and one electron under alkaline conditions. The reactions of permanganate due to $\mathrm{pH}$ changes are as in Equations 1,2, and 3 (Xu et al. 2017; Yin et al. 2017; Xu et al. 2016).

$$
\begin{array}{crrr}
\mathrm{MnO}_{4}^{-}+8 \mathrm{H}^{+}+5 e^{-} \rightarrow \mathrm{Mn}^{2+}+4 \mathrm{H}_{2} \mathrm{O} & E^{0}=1.51 \mathrm{~V} & \text { (acidic conditions) } \\
\mathrm{MnO}_{4}^{-}+2 \mathrm{H}_{2} \mathrm{O}+3 e^{-} \rightarrow \mathrm{MnO}_{2}++\mathrm{OH}^{-} & E^{0}=0.58 \mathrm{~V} & \text { (neutral conditions) } \\
\mathrm{MnO}_{4}^{-}+e^{-} \rightarrow \mathrm{MnO}_{4}^{2-} & E^{0}=0.56 \mathrm{~V} & \text { (alkaline conditions) }
\end{array}
$$

Ozone is a very strong oxidant (redox potential of $2.07 \mathrm{~V}$ ). Through the special dipole structure, it reacts rapidly with organic and inorganic materials in aqueous solutions (Li et al. 2018). Depend on $\mathrm{pH}$ changes two types of reactions occur as direct and indirect in the oxidation of wastewater with ozone (Waldemer et al. 2010).

The direct and indirect reactions of ozone are as follows in Equations 4 and 5:

Direct reactions:

$$
\mathrm{O}_{3}+\mathrm{R} \rightarrow \text { Products }
$$

Indirect reactions: (total reaction)

$$
3 \mathrm{O}_{3}+\mathrm{H}_{2} \mathrm{O} \rightarrow 2 \mathrm{OH}^{\cdot}+4 \mathrm{O}_{2}
$$


In this study, the effects of $\mathrm{pH}$ on the treatment efficiency of ECBD wastewater were investigated by using advanced oxidation processes of $\mathrm{KMnO}_{4}$ and $\mathrm{KMnO}_{4} / \mathrm{O}_{3}$. Experiments were conducted at a dose of $1 \mathrm{~g} / \mathrm{L} \mathrm{KMnO}_{4}$ and $600 \mathrm{mg} / \mathrm{L} \mathrm{O}_{3}$, reaction time of 1 hour at chosen $\mathrm{pH}$ values (between 2 and 13). After implementing both methods, removal efficiencies were determined by measuring $\mathrm{COD}$ and $\mathrm{MeOH}$ parameters in ECBD wastewater. The Figure 2 shows the $\mathrm{COD}$ and $\mathrm{MeOH}$ removal efficiencies for both processes.

In the $\mathrm{KMnO}_{4}$ process, while the maximum COD removal efficiency was observed at $\mathrm{pH} 2$, a decreasing trend was observed with the $\mathrm{pH}$ increase. If numerically expressed, whereas the COD removal efficiency was $83.99 \%$ at $\mathrm{pH} 2$, was $78.59 \%$ at $\mathrm{pH} 13$. As can be seen from Figure 2, if the removal of $\mathrm{MeOH}$ is examined, a similar situation is observed with $\mathrm{COD}$. The highest $\mathrm{MeOH}$ removal efficiency was obtained at $\mathrm{pH} 2$ as $90.78 \%$. Under acidic conditions, $\mathrm{MnO}^{4-}$ get the highest $\mathrm{E}^{0}$ (electrode potential) value. Due to the $\mathrm{pH}$ increment, $\mathrm{E}^{0}$ decreases caused removal efficiencies to fall away. In the research conducted with p-Arsanilic acid and roxarsone, researchers achieved high efficiency in reduction of these substances with permanganate under acidic $(\mathrm{pH} 2-7)$ conditions (Xiea et al. 2019).

In the oxidation of sulfadiazine with permanganate, close to $100 \%$ at $\mathrm{pH} 3.76$ was removed in 10 minutes (Yang et al. 2018) has been reported that the chemical properties of organic compounds may play a role in the reactions with permanganate. For example, the highest removal efficiency of trichloracan was determined as $\mathrm{pH} 8$. (Jiang et al. 2009).

The COD removal efficiency in the $\mathrm{KMnO}_{4} / \mathrm{O}_{3}$ process shows a gentle increasing trend depending on $\mathrm{pH}$. The COD removal efficiency was $81.95 \%$ at $\mathrm{pH} 2$ and rises up to $85.50 \%$ at $\mathrm{pH}$ 13. Also, in the same process, determined that the $\mathrm{MeOH}$ removal was not changed significantly depending on the $\mathrm{pH}$ as clearly seen in Figure 2. While at pH 2 the $\mathrm{MeOH}$ removal efficiency was 89.60\%, at pH 13 the highest removal performance was observed as $92.32 \%$. Ozone oxidation performs with indirect reactions by generating $\mathrm{OH}^{\cdot}$ radical at high $\mathrm{pH}$ 's. Since the $\mathrm{E}^{0}$ value of the generated $\mathrm{OH}^{*}$ radicals were higher, it has been observed that the removal efficiency increases at high $\mathrm{pH}$. Although there are many studies in the literature about the treatment of biodiesel wastewater, none using $\mathrm{KMnO}_{4} / \mathrm{O}_{3}$ and $\mathrm{KMnO}_{4}$ processes. The oxidation of 
ECBD wastewater with ozone studied and the highest removal efficiency was determined as pH 13.9 (Tanatt et al. 2019). Due to the formation of oh radicals at high $\mathrm{pH}$ in the treatment of pharmaceutical wastewater with ozone, experiments were conducted at pH 12.9 (Zhan et al. 2019).

\subsection{Effect of $\mathrm{KMnO}_{4}$ dose in $\mathrm{KMnO}_{4}$ and $\mathrm{KMnO}_{4} / \mathrm{O}_{3}$ processes}

Oxidant dose has a significant effect on the breakdown of organic compounds (Xie et al. 2019). For both processes, studies were conducted between $0.5 \mathrm{~g} / \mathrm{L}$ and $7.5 \mathrm{~g} / \mathrm{L}$ $\mathrm{KMnO}_{4}$ doses to investigate the effects of $\mathrm{KMnO}_{4}$ dose on treatment efficiency in ECBD wastewater. In the previous $\mathrm{pH}$ determination studies conducted, the optimum $\mathrm{pH}$ was determined as 2 for the $\mathrm{KMnO}_{4}$ process and as 13 for the $\mathrm{KMnO}_{4} / \mathrm{O}_{3}$ process. For both processes, studies were maintained with $600 \mathrm{mg} / \mathrm{L}$ as ozone dose and 1 hour as the reaction time. The results obtained are shown in Figure 3. COD and $\mathrm{MeOH}$ removal efficiencies showed similar trends in studies with different $\mathrm{KMnO}_{4}$ doses in the $\mathrm{KMnO}_{4}$ process. The $\mathrm{COD}$ and $\mathrm{MeOH}$ removal efficiencies increased rapidly up to the addition of $5 \mathrm{~g} / \mathrm{L} \mathrm{KMnO}_{4}$, not showed a significant gain after this point. As can be seen from Figure 3, the $\mathrm{COD}$ and $\mathrm{MeOH}$ removal efficiencies of $81.82 \%$ and 89.11, respectively, with the addition of $0.5 \mathrm{~g} / \mathrm{L} \mathrm{KMnO}_{4}$, varied as $86.87 \%$ and $92.92 \%$ at the $5 \mathrm{~g} / \mathrm{L} \mathrm{KMnO}_{4}$ dose. On the other hand, at a dose of $7.5 \mathrm{~g} / \mathrm{L} \mathrm{KMnO}_{4}$, the COD and $\mathrm{MeOH}$ removal efficiencies were $87.02 \%$ and $92.97 \%$. In a study conducted with pulp and paper wastewater, it was determined that removal efficiencies increased with the permanganate dose increment, the significant change did not observe after $1.5 \mathrm{mM}$ dose (Jaafarzadeh et al. 2017). In another study, it was founded that with the permanganate dose rise the treatment of Triclosan advanced up to 100\% (Chen et al. 2016)

According to the experimental results in the $\mathrm{KMnO}_{4} / \mathrm{O}_{3}$ process, $\mathrm{COD}$ removal efficiency was reached the maximum level at a dose of $2 \mathrm{~g} / \mathrm{L} \mathrm{KMnO}_{4}$. Over this dose, $\mathrm{KMnO}_{4}$ did not have an extra effect on COD removal and created a stable trend. Regarding the $\mathrm{MeOH}$ removal, up to a dose of $2 \mathrm{~g} / \mathrm{L} \mathrm{KMnO}_{4}$ has showed a rapid increase. Above this dose the $\mathrm{MeOH}$ removal yields were determined as about average 
$0.15 \%$. At the dose of $2 \mathrm{~g} / \mathrm{L} \mathrm{KMnO} 4, \mathrm{COD}$ and $\mathrm{MeOH}$ removal efficiencies were obtained as $88.47 \%$ and $94.58 \%$, respectively.

\subsection{Effect of $\mathrm{O}_{3}$ dose in $\mathrm{KMnO}_{4}$ and $\mathrm{KMnO}_{4} / \mathrm{O}_{3}$ processes}

Ozone dose is one of the most important parameters affecting the treatment efficiency of the $\mathrm{KMnO}_{4} / \mathrm{O}_{3}$ process. With the increase of the ozone dose, the formation of $\mathrm{OH}$ radicals in the process also rises. The study was carried out with varying ozone doses as 300, 600, 1000, 1500, 3000 and $9000 \mathrm{mg} / \mathrm{L}$, keeping $\mathrm{pH} 13, \mathrm{KMnO}_{4}$ dose $2 \mathrm{~g} / \mathrm{L}$ and 1 hour reaction time constant. The Figure 4 shows the effect of ozone dose on COD and $\mathrm{MeOH}$ removal efficiencies. $\mathrm{COD}$ removal efficiencies at these ozone doses were found to be $80.31,82.01,82.57,83.65,85.14$ and $85.35 \%$, respectively. $\mathrm{MeOH}$ removal efficiencies were obtained as 90.14, 90.92, 91.12, 91.58, 93.38 and 93.18\%, respectively. Up to $3000 \mathrm{mg} / \mathrm{L}$, ozone dose removal efficiencies rises in conjunction with the ozone flow, after this point the increase is negligible. The solubility of ozone in wastewater is limited, so after the saturation with ozone, the increased ozone dose has no extra effect on the removal efficiency (Deng 2020).

\subsection{Effect of reaction time in $\mathrm{KMnO}_{4}$ and $\mathrm{KMnO}_{4} / \mathrm{O}_{3}$ processes}

In the experiments conducted in both processes within the scope of the study, was carried out between 0.25 hours and 6 hours to determine the reaction time. The effects of the reaction time on the $\mathrm{COD}$ and $\mathrm{MeOH}$ removal efficiency were investigated by using the optimum parameters $\left(\mathrm{pH} 2,5 \mathrm{~g} / \mathrm{L} \mathrm{KMnO}_{4}\right)$ in the $\mathrm{KMnO}_{4}$ process. According to Figure 5, in the $\mathrm{KMnO}_{4}$ process, $\mathrm{COD}$ and $\mathrm{MeOH}$ removal efficiencies increased with longer reaction times. However, the increase in removal efficiencies after 3 hours is an insignificant level. When the experimental results were examined, the COD removal efficiency was $79.91 \%$ in the 0.25 hour reaction time, while it was $91.74 \%$ in the 6 hour reaction time. At the reaction time of 0.25 hours, $85.02 \%$ of the existing $\mathrm{MeOH}$ in the biodiesel wastewater was removed, at the end of 6 hours, $95.83 \%$ removal was achieved.

Studies to determine the effect of reaction time in $\mathrm{KMnO}_{4} / \mathrm{O}_{3}$ process were carried out with $\mathrm{pH}$ 13, $2 \mathrm{~g} / \mathrm{L} \mathrm{KMnO}_{4}$ and $3000 \mathrm{mg} / \mathrm{L} \mathrm{O}_{3}$ dose. In the $\mathrm{KMnO}_{4} / \mathrm{O}_{3}$ process, COD 
and $\mathrm{MeOH}$ removal efficiencies increase with the extension of the reaction time as in the $\mathrm{KMnO}_{4}$ process. When Figure 5 is examined, $\mathrm{COD}$ and $\mathrm{MeOH}$ removal yields were obtained as $85.97 \%$ and 87.33 , respectively, at a reaction time of 0.25 hours. However, in the reaction time of 6 hours, $97.79 \%$ of COD is removed and the $\mathrm{MeOH}$ removal efficiency has observed as $98.30 \%$.

\subsection{Kinetic analysis of $\mathrm{COD}$ and $\mathrm{MeOH}$ removal efficiencies in in $\mathrm{KMnO}_{4}$ and $\mathrm{KMnO}_{4} / \mathrm{O}_{3}$ processes}

Kinetic parameters are obtained using experimental data. Reaction rate constants and regression coefficients can be achieved by using kinetic modeling (Kaur et al. 2020). In the study, first order, second order and pseudo-first-order, pseudo-second-order kinetic models, which are widely used in the literature, were examined for $\mathrm{KMnO}_{4}$ and $\mathrm{KMnO}_{4} / \mathrm{O}_{3}$ processes.

In the study, first order, second order and pseudo-first-order, pseudo-second-order kinetic models, which are widely used in the literature, were examined for $\mathrm{KMnO}_{4}$ and $\mathrm{KMnO}_{4} / \mathrm{O}_{3}$ processes. The equations of the used kinetic models are given below (Simonin, 2016; Bener et al. 2019; Samal and Trivedi 2020; Titchou et al. 2020).

$$
\begin{gathered}
\ln \frac{C_{0}}{C}=k \cdot t \\
\frac{1}{C}-\frac{1}{C_{0}}=k \cdot t \\
\ln \left[C_{e}-C_{(t)}\right]=\ln C_{e}-k \cdot t \\
\frac{t}{C}=\frac{1}{k_{2} \cdot C_{e}^{2}}+\frac{1}{C_{e}} \cdot t
\end{gathered}
$$

Where; Co: Inital concentration (mg/L), C: Final concentration (mg/L), t: Reaction time (min), Ce: Concentration coefficient $(\mathrm{mg} / \mathrm{L}), \mathrm{k}_{2}$ : Mean mass transport coefficient $(1 / \mathrm{min})$.

The reaction rate constants $(\mathrm{k})$ and regression coefficient $\left(\mathrm{R}^{2}\right)$ values for the COD and $\mathrm{MeOH}$ parameters obtained with the kinetic examination performed for the $\mathrm{KMnO}_{4}$ process are given in the Table 2. Four models were examined separately and the highest $R^{2}$ values were reached with the pseudo $2^{\text {nd }}$ order model. While the $R^{2}$ value 
obtained as 0.9999 for COD with the pseudo $2^{\text {nd }}$ order model, for the $\mathrm{MeOH}$ removal was achieved as 1 with the same model. $\mathrm{k}$ values were found as $0.00006 \mathrm{~L} / \mathrm{mg}$.min and $0.000163 \mathrm{~L} / \mathrm{mg}$.min for COD and $\mathrm{MeOH}$, respectively.

The reaction rate constants $(\mathrm{k})$ and the regression coefficient $\left(\mathrm{R}^{2}\right)$ in the kinetic analysis for the $\mathrm{COD}$ and $\mathrm{MeOH}$ parameters in the $\mathrm{KMnO}_{4} / \mathrm{O}_{3}$ process are given in the Table 3. The highest $\mathrm{R}^{2}$ values among the examined kinetic models were obtained in the pseudo $2^{\text {nd }}$ order model. The determined $\mathrm{R}^{2}$ values by the kinetic examination for the $\mathrm{COD}$ and $\mathrm{MeOH}$ parameters are 0.9994 and 0.9999 , respectively as shown in Table 3. $\mathrm{k}$ values were spesified for $\mathrm{COD}$ and $\mathrm{MeOH}$ removal as $0.00006 \mathrm{~L} / \mathrm{mg}$.min and $0.00016 \mathrm{~L} / \mathrm{mg} \cdot \mathrm{min}$.

Theoretical and experimental removal efficiencies obtained by the pseudo $2^{\text {nd }}$ order models for $\mathrm{KMnO}_{4}$ and $\mathrm{KMnO}_{4} / \mathrm{O}_{3}$ processes and results are given in Figure 6 and 7. As seen in Figure 6, the COD removal efficiency rapidly increases in the first 90 minutes, and then it slows down. In the comparison of the experimental and theoretical results, both results overlap in the longer time periods. However, as seen in Figure 7, the $\mathrm{MeOH}$ removal efficiencies given theoretically and experimentally are in agreement. As with $\mathrm{COD}, \mathrm{MeOH}$ removal efficiencies increase slowly depending on time.

\section{Conclusions}

Two different advanced oxidation processes have been used on the electrocoagulated biodiesel wastewater treatment. The optimum conditions for $\mathrm{KMnO}_{4}$ process have determined as $\mathrm{pH} 2,5 \mathrm{~g} / \mathrm{L} \mathrm{KMnO}_{4}$ dose and 6 hour reaction time. Moreover, the optimum conditions for $\mathrm{KMnO}_{4} / \mathrm{O}_{3}$ process have determined as $\mathrm{pH} 13,2 \mathrm{~g} / \mathrm{L} \mathrm{KMnO} 4$ dose $3000 \mathrm{mg} / \mathrm{L} \mathrm{O}_{3}$ dose and 6 hour reaction time. Therefore, under the optimum conditions, the COD removal efficiencies for $\mathrm{KMnO}_{4}$ and $\mathrm{KMnO}_{4} / \mathrm{O}_{3}$ processes was obtained as $91.74 \%$ and $97.79 \%$, respectively. Furthermore, the $\mathrm{MeOH}$ removal efficiencies for $\mathrm{KMnO}_{4}$ and $\mathrm{KMnO}_{4} / \mathrm{O}_{3}$ processes was obtained as $95.93 \%$ and $98.30 \%$, respectively. The result of this study was verified that the COD and $\mathrm{MeOH}$ 
removals were reached the highest efficiency for both processes, whereas, comparing to the $\mathrm{KMnO}_{4}$ process, it has seen that $\mathrm{KMnO}_{4} / \mathrm{O}_{3}$ process removal efficiency is higher than the $\mathrm{KMnO}_{4}$ process.

The observation of the $\mathrm{KMnO}_{4}$ and the $\mathrm{KMnO}_{4} / \mathrm{O}_{3}$ processes show that with 6 hour reaction time obtained COD values $1421.36 \mathrm{mg} / \mathrm{L}$ and $380.1 \mathrm{mg} / \mathrm{L}$ respectively. According to the water pollution and control regulation in Turkey, the COD limit value is $400 \mathrm{mg} / \mathrm{L}$ for biodiesel wastewater to discharge to the receiving environment. With this scope, the comparison of the $\mathrm{KMnO}_{4}$ and $\mathrm{KMnO}_{4} / \mathrm{O}_{3}$ processes for COD parameter shows that with the $\mathrm{KMnO}_{4}$ longer reaction time is necessary to achieve regulation standards for biodiesel wastewater treatment. However, in the $\mathrm{KMnO}_{4} / \mathrm{O}_{3}$ process, with shorter reaction time COD can be reduced to the limit value.

Availability of data and materials: All the results is original, availability of data and materials has not been used in this manuscript.

Competing interests/Conflict of interest: There is no competing interests/ conflict of interest about this manuscript.

Funding: There is no any funding that supports this manuscript.

Author Contributions: N.P.T (Ph.D.) conducted treatment experiment, wrote and revised manuscript. I read and approved the final manuscript.

\section{References}

Ahmadi S, Sardari E, Javadian HR, Katal R, Sefti MV (2013) Removal of oil from biodiesel wastewater by electrocoagulation method. Korean J Chem Eng 30(3): 634641.

Althagafi II, Fawzy A (2016) Kinetics and Mechanistic Study of Permanganate Oxidation of L-Citrulline in Acidic and Basic Media. Amer J Phy Chem 5: 99-107.

APHA/AWWA/WEF (2017) Standard Methods for the Examination of Water and Wastewater Stand Methods 541.

Atadashi IM, Aroua MK, Abdul-Aziz AR, Sulaiman NMN (2011) Refining technologies for the purification of crudebiodiesel. Appl Energy 88:(12) 4239-4251.

Bener S, Bulca Ö, Palas B, Tekin G, Atalay S, Ersöz G (2019) Electrocoagulation process for the treatment of real textilewastewater: Effect of operative conditions on the organic carbonremoval and kinetic study. Proc Safety Environ Protec 129:47-54. 
Berrios M, Skelton RL, (2008) Comparison of purification methods for biodiesel. Chem Eng J 144: 459-465.

Chen J, Qu R, Pan X, Wang Z (2016) Oxidative degradation of triclosan by potassium permanganate: Kinetics, degradation products, reaction mechanism, and toxicity evaluation. Water Res 103:215-223.

Chi X, Li A, LiaM, Ma L, Tang Y, Hu B, Yang J (2018) Influent characteristics affect biodiesel production from waste sludge in biological wastewater treatment systems. Inter Biodete Biodegr 132:226-235.

Daud Z, Awang H, Latif AAA, Nasir N, Ridzuan MB, Ahmad Z (2015) Suspended solid, color, COD and oil and grease removal from biodiesel wastewater by coagulation and flocculation processes. Procedia Soc Behav Sci.195: 2407-2411.

Daud NM, Abdullah SR, Abu-Hasan H (2018) Response surface methodological analysis for the optimization of acid-catalyzed transesterification biodiesel wastewater pre-treatment using coagulation-flocculation process, Process Saf Environ Prot 113: 184-192.

Deng H (2020) Ozonation mechanism of carbamazepine and ketoprofen in RO concentrate from municipal wastewater treatment: Kinetic regimes, removal efficiency and matrix effect. Sci Total Environ 717:137150.

Gong H, Chu W (2018) Permanganate with a double-edge role in photodegradation of sulfamethoxazole: Kinetic, reaction mechanism and toxicity. Chemos 191:494-502.

Jaafarzadeh N, Ghanbari F, Ahmadi M, Omidinasab M (2017) Efficient integrated processes for pulp and paper wastewater treatment and phytotoxicity reduction: Permanganate, electro-Fenton and $\mathrm{Co}_{3} \mathrm{O}_{4} /$ UV/peroxymonosulfate. Chem Eng J 308: $142-150$.

Jaruwat P, Kongjao S, Hunsom M (2010) Management of biodiesel wastewater by the combined processes of chemical recovery and electrochemical treatment. Energy Conv Manag 51:531-537.

Jiang J, Pang SY, Ma J (2009) Oxidation of triclosan by permanganate (Mn(VII)): importance of ligands and in situ formed manganese oxides. Environ Sci Technol 43: 8326-8331.

Kaur P, Imteaz MA, Sillanp M, Sangal VK, Kushwaha JP (2020) Parametric optimization and MCR-ALS kinetic modeling of electro oxidation process for the treatment of textile wastewater. Chemo Intel Lab Sys 203:104027.

Li X, Chen W, Ma L, Wang H, Fan J (2018) Industrial wastewater advanced treatment via catalytic ozonation with an Fe-based catalyst. Chemos 195: 336 -343. 
Mohana V, Gowda B, Pramila CK, Prasanna KT (2011) Biodiesel Spentwash: Characterization, Amelioration and its effect on Seed Germination, Seedling Growth and Biochemical Parameters of French bean (Phaseolus vulgaris L.). Int J Env Sci 2:1039-1047.

Mozaffarikhah K, Kargari A, Tabatabaei M, Ghanavati H, Shirazi MMA (2017) Membrane treatment of biodiesel wash-water: A sustainable solution for water recycling in biodiesel production process. J Wat Proc Eng 19: 331-337.

Nawrocki J, Kasprzyk-Hordern B (2010) The efficiency and mechanisms of catalytic ozonation. Appl Catal B Environ 99: 27-42.

Ngamlerdpokin K, Kumjadpai S, Chatanon P, Tungmanee U, Chuenchuanchom S, Jaruwat P, Lertsathitphongs P, Hunsom M (2011) Remediation of biodiesel wastewater by chemical- and electro-coagulation:A comparative study. J Environ Manag 92:2454-2460.

Nishio N, Nakashimada Y (2007) Recent development of anaerobic digestion processes for energy recovery from wastes. J Biosci Bioeng 103:105-112.

Pang SY, Jiang J, Gao Y, Zhou Y, Huangf X., Liu Y, Ma J (2014) Oxidation of flame retardant tetrabromobisphenol $\mathrm{A}$ by aqueous permanganate: reaction kinetics, brominated products, and pathways. Environ Sci Technol 48: 615-623.

Patiño Y, Mantecón LG, Polo S, Faba L, Díaz E, Ordóñez S (2018) Effect of sludge features and extraction-esterification technology on the synthesis of biodiesel from secondary wastewater treatment sludges. Biores Technol 247:209-216.

Pazdzior K, Wrebiak J, Klepacz-Smołka A, Gmurek M, Bilinska L, Kos L, SojkaLedakowicz J, Ledakowicz S (2017) Influence of ozonation and biodegradation on toxicity of industrial textile wastewater. J Environ Manag 195:166-173.

Pitakpoolsil W, Hunsom M (2014) Treatment of biodiesel wastewater by adsorption with commercial chitosan flakes: Parameter optimization and process kinetics. J Env Manag 133: 284-292.

Rattanapan C, Sawain A, Suksaroj T, Suksaroj C (2011) Enhanced efficiency of dissolved air flotation for biodieselwastewater treatment by acidification and coagulationprocesses. Desal 280:370-377.

Rodriguez E, Majado ME, Meriluoto J, Acero JL (2007) Oxidation of microcystins by permanganate: reaction kinetics and implications for water treatment. Water Res 41:102-110.

Romero JAP, Cardoso-Junior FSS, Figueiredo RT, Silva DP, Cavalcanti EB (2013) Treatment of biodiesel wastewater by combined electroflotation and electrooxidation processes. Sep Sci Technol48:2073-2079. 
Samal K, Trivedi S (2020) A statistical and kinetic approach to develop a Floating Bed for the treatment of wastewater. J Environ Chem Eng 8:104102.

Siles JA, Martín MA, Chica AF, Martín A (2010) Anaerobic co-digestion of glycerol and wastewater derived from biodiesel manufacturing. Bioresour Technol 101:63156321.

Simonin JP (2016) On the comparison of pseudo-first order and pseudo-second order rate laws in the modeling of adsorption kinetics. Chem Eng J 300:254-263.

Song D, Jefferson WA, Cheng H, Jiang X, Qiang Z, He H, Liu H, Qu J (2019) Acidic permanganate oxidation of sulfamethoxazole by stepwise electron-proton transfer. Chemos 222: 71-82.

Srirangsan A, Ongwandee M, Chavalparit O (2009) Treatment of biodiesel wastewater by electrocoagulation process. Environ Asia 2:15-19.

Suehara K, Kawamoto Y, Fujii E, Kohda J, Nakano Y, Yano T (2005) Biological treatment of wastewater discharged from biodiesel fuel production plant with alkalicatalyzed transesterification. J Biosci Bioeng 100:437-442.

Tanattı P, Şengil İA, Özdemir A (2018) Optimizing TOC and COD removal for the biodiesel wastewater by electrocoagulation. App Wat Sci 8:58.

Tanattı P, Şengil İA, Özdemir A (2018) Treatment of biodiesel wastewater by solvent extraction: Evaluation of kinetic and thermodynamic data. Environ Eng Manag J 11:2657-2665.

Tanatti NP, Mehmetbaşoğlu M, Şengil İA, Aksu H, Emin E (2019) Kinetics and thermodynamics of biodiesel wastewater treatment by using ozonation process. Desal Water Treat 161:108-115.

Titchou FE, Akbour RA, Assabbane A, Hamdani M (2020) Removal of cationic dye from aqueous solution using Moroccan pozzolana as adsorbent: Isotherms, kinetic studies, and application on real textile wastewater treatment. Groundwat Susta Develop 11:100405.

Veljkovi'c VB, Stamenkovi'c OS, Tasi'c MB (2014) Thewastewater treatment in the biodiesel production withalkali-catalyzed transesterification. Renew Sustain EnergyRev 32:40-60.

Waldemer RH, Gottschalk PGC, Libra JA, Saupe A (2010) Ozonation of Water and Waste Water, A Practical Guide to Understanding Ozone and its Applications. 2nd Ed, Wiley-VCH, Germany.

Xie X, Zhao W, Hu Y, Xu X, Cheng H (2019) Permanganate oxidation and ferric ion precipitation $(\mathrm{KMnO} 4-\mathrm{Fe}(\mathrm{III}))$ process for treating phenylarsenic compounds. Chem Eng J 357: 600-610. 
Xu K, Ben W, Ling W, Zhang Y, Qu J, Qiang Z (2017) Impact of humic acid on the degradation of levofloxacin by aqueous permanganate: Kinetics and mechanism. Water Res 123:67-74.

Xu X, Chen J, Wang S, Ge J, Qu R, Feng M, Sharma VK, Wang Z (2018) Degradation kinetics and transformation products of chlorophene by aqueous permanganate. Water Res 138:293-300.

Xu Y, Liu S, Guo F, Zhang B, Yang JF, He M, Wu TF, Hao AP, Zhang SB (2016) Evaluation of the oxidation of enrofloxacin by permanganate and the antimicrobial activity of the products. Chemos144:113-121.

Yang J, Li J, Zhu J, Dong Z, Luo F, Wang Y, Liu H, Jiang C, Yuan H (2017) A novel design for an ozone contact reactor and its performance on hydrodynamics, disinfection, bromate formation and oxidation. Chem Eng J 328:207-214.

Yang JF, He M, Wud TF, Hao AP, Zhang SB, Chen YD, Zhou SB, Zhen LY, Wang R, Yuan ZL, Deng L (2018) Sulfadiazine oxidation by permanganate: Kinetics, mechanistic investigation and toxicity evaluation. Chem Eng J 349: 56-65.

Yin K, Li F, Wang Y, He Q, Deng Y, Chen S, Liu C (2017) Oxidative transformation of artificial sweetener acesulfame bypermanganate: Reaction kinetics, transformation products andpathways, and ecotoxicity. J Hazard Mater 330:52-60.

Zhan J, Li Z, Yu G, Pan X Wang J, Zhu W, Han X, Wang Y (2019) Enhanced treatment of pharmaceutical wastewater by combining threedimensional electrochemical process with ozonation to in situ regenerate granular activated carbon particle electrodes. 208: 12-18.m

Zhan YY, Zhang Y, Li QM, Du XZ (2010) A Novel Visible Spectrophotometric Method for the Determination of Methanol Using Sodium Nitroprusside as Spectroscopic Probe. J Chinese Chem Soc 57: 230-235.

Zhang J, Sun B, Guan X (2013) Oxidative removal of bisphenol A by permanganate: Kinetics, pathways and influences of co-existing chemicals. Sep Purif Technol 107: $48-53$.

Zhang J, Sun B, Xiong X, Gao N, Song W, Du E, Guan X, Zhou G (2014) Removal of emerging pollutants by $\mathrm{Ru} / \mathrm{TiO} 2$ - catalyzed permanganate oxidation. Water Res 63:262-270.

Zhong S, Zhang $\mathrm{H}$ (2019) New insight into the reactivity of $\mathrm{Mn}(\mathrm{III})$ in bisulfite/permanganate for organic compounds oxidation: The catalytic role of bisulfite and oxygen. Water Res 148:198-207. 

Table 1. The characterization of electrocoagulated biodiesel wastewater (ECBD)

\begin{tabular}{ll}
\hline Parameter & Value \\
\hline $\mathrm{pH}$ & 7,8 \\
\hline Oil-Gress $(\mathrm{mg} / \mathrm{L})$ & 25 \\
\hline $\mathrm{COD}(\mathrm{mg} / \mathrm{L})$ & 17200 \\
\hline $\mathrm{TOC}(\mathrm{mg} / \mathrm{L})$ & 5520 \\
\hline $\mathrm{MeOH}(\mathrm{mg} / \mathrm{L})$ & 6230 \\
\hline
\end{tabular}

Table 2. $\mathrm{R}^{2}$ and $\mathrm{k}$ values as per kinetic models in $\mathrm{KMnO}_{4}$ process

\begin{tabular}{|c|c|c|c|c|}
\hline \multirow{2}{*}{ Kinetic model } & \multicolumn{2}{|c|}{ COD } & \multicolumn{2}{|c|}{$\mathrm{MeOH}$} \\
\hline & $\mathbf{R}^{2}$ & $\mathbf{k}$ & $\mathbf{R}^{2}$ & $\mathbf{k}$ \\
\hline $1^{\text {st }}$ order* & 0.7827 & 0.00227 & 0.666 & 0.00282 \\
\hline $2^{\text {nd }}$ order $^{* *}$ & 0.87064 & 0.000001 & 0.80351 & 0.000007 \\
\hline Pseudo $1^{\text {st }}$ order ${ }^{* * *}$ & 0.90537 & 0.00834 & 0.88627 & 0.011154 \\
\hline Pseudo $2^{\text {nd }}$ order ${ }^{* * * * *}$ & 0,9999 & 0.00006 & 0,99999 & 0.000163 \\
\hline
\end{tabular}

Table 3. $\mathrm{R}^{2}$ and $\mathrm{k}$ values as per kinetic models in $\mathrm{KMnO}_{4} / \mathrm{O}_{3}$ process

\begin{tabular}{lllll}
\hline \multirow{2}{*}{ Kinetic model } & COD & \multicolumn{3}{l}{ MeOH } \\
\cline { 2 - 5 } & $\mathbf{R}^{\mathbf{2}}$ & $\mathbf{k}$ & $\mathbf{R}^{\mathbf{2}}$ & $\mathbf{k}$ \\
\hline $\mathbf{1}^{\text {st }}$ order* $^{*}$ & 0.9771 & 0.00576 & 0.9171 & 0.00528 \\
$\mathbf{2}^{\text {nd }}$ order $^{* *}$ & 0.9363 & 0.000007 & 0.99 & 0.00002 \\
Pseudo 1 $^{\text {st }}$ order $^{* * *}$ & 0.9335 & 0.01045 & 0.9715 & 0.01095 \\
Pseudo 2 $^{\text {nd }}$ order $^{* * * *}$ & 0,9994 & 0.00006 & 0,9999 & 0.00016
\end{tabular}

$1^{\text {st }} \operatorname{order}^{*} \mathrm{k}$ unit: $1 / \mathrm{min}, 2^{\text {nd }} \operatorname{order}^{* * *} \mathrm{k}$ unit: L/mg.min, Pseudo $1^{\text {st }} \operatorname{order}^{* * *} \mathrm{k}$ unit: $\mathrm{mg} / \mathrm{L} \cdot \min$, Pseudo $2^{\text {nd }} \operatorname{order}^{* * * * *} \mathrm{k}$ unit: L/mg.min 


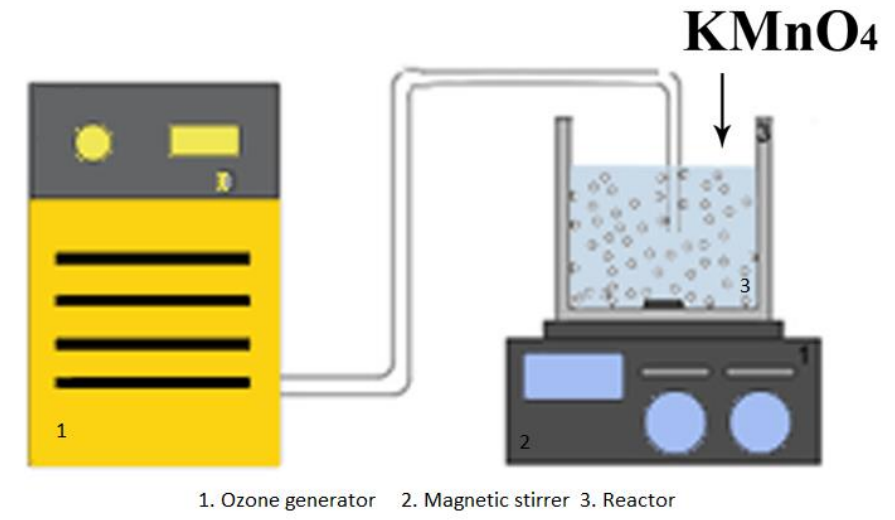

Figure $1 . \mathrm{O}_{3}$ process experimental setup

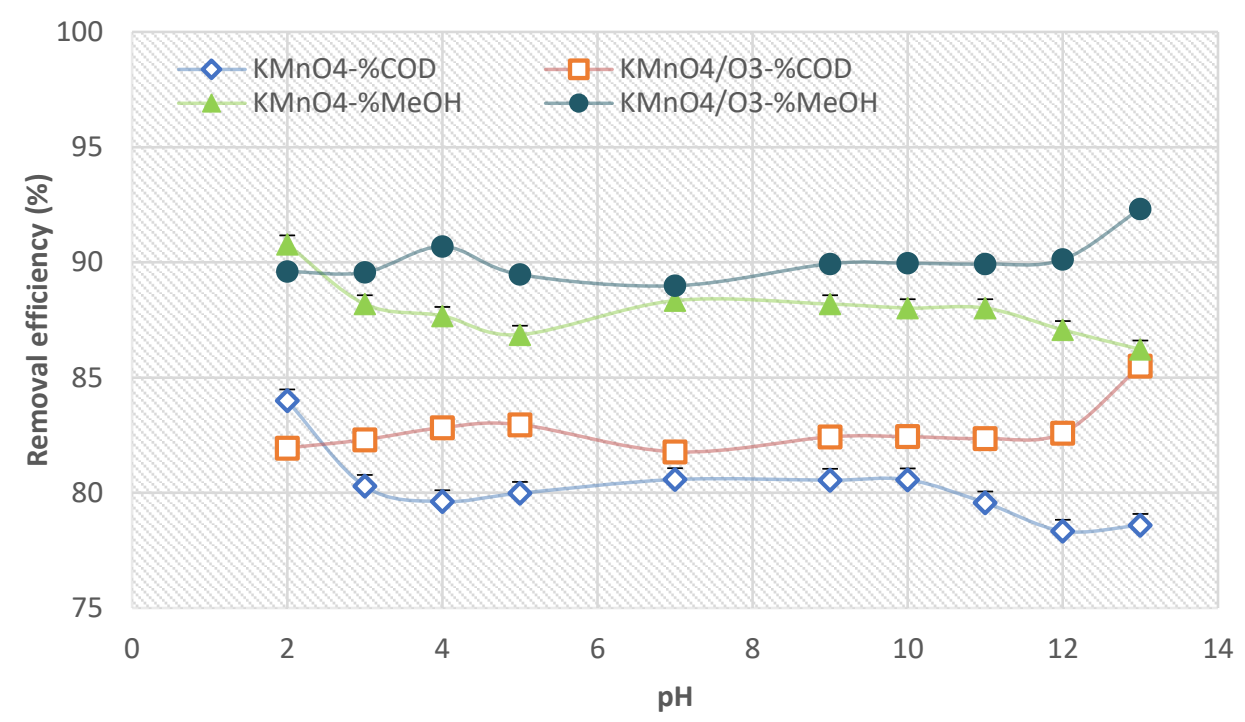

Figure 2. The effect of $\mathrm{pH}$ on the $\mathrm{COD}$ and $\mathrm{MeOH}$ removal efficiency $\left(\mathrm{C}_{\mathrm{o}, \mathrm{COD}}=17200 \mathrm{mg} / \mathrm{L} ; \mathrm{C}_{\mathrm{o}, \mathrm{MeOH}}=6375 \mathrm{mg}\right.$ $/ \mathrm{L} ; \mathrm{KMnO}_{4}$ dose $=1 \mathrm{~g} / \mathrm{L} ; \mathrm{O}_{3}$ dose $=600 \mathrm{mg} / \mathrm{L} ; \mathrm{t}=1 \mathrm{~h}$ ) 


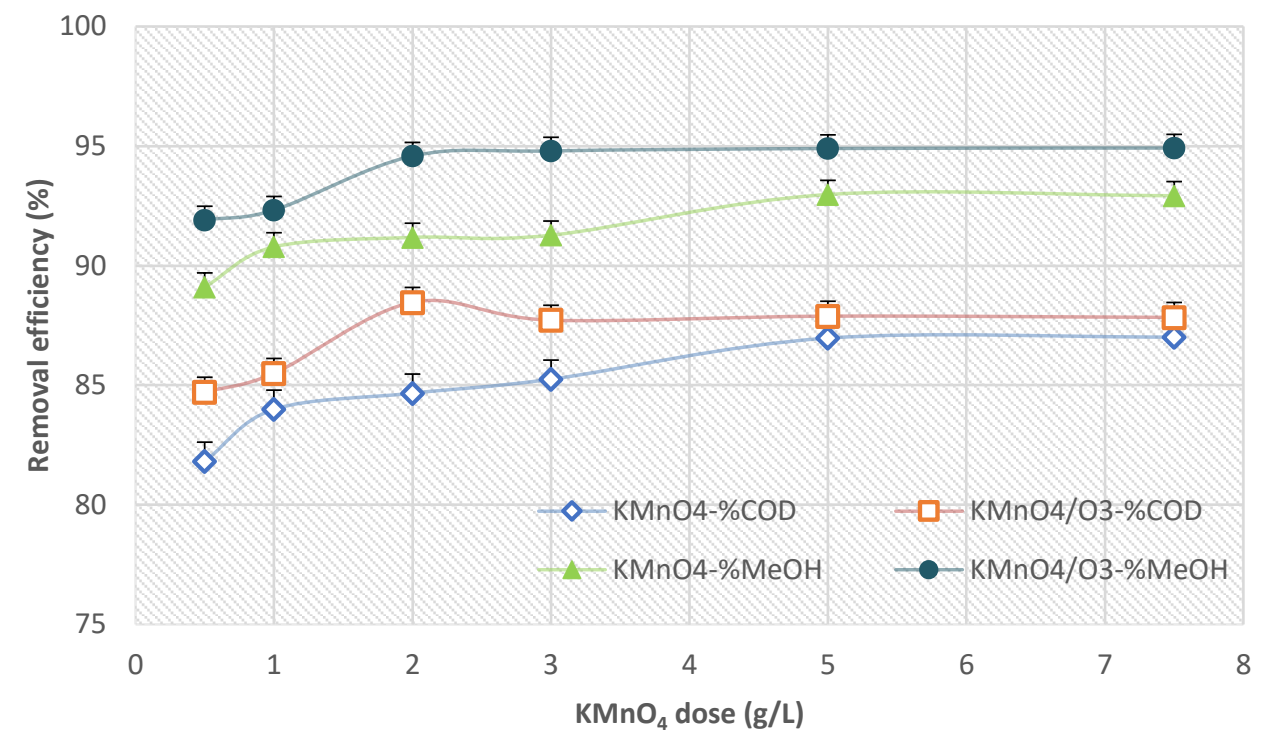

Figure 3. The effect of $\mathrm{KMnO}_{4}$ dose on the $\mathrm{COD}$ and $\mathrm{MeOH}$ removal efficiency $\left(\mathrm{C}_{\mathrm{o}, \mathrm{COD}}=17200 \mathrm{mg} / \mathrm{L} ; \mathrm{C}_{\mathrm{o}, \mathrm{MeOH}}=\right.$ $6375 \mathrm{mg} / \mathrm{L} ; \mathrm{pH}_{\mathrm{KMnO} 4} 2 ; \mathrm{pH}_{\mathrm{KMnO} 4 / \mathrm{O} 3} 13 ; \mathrm{O}_{3}$ dose $=600 \mathrm{mg} / \mathrm{L} ; \mathrm{t}=1 \mathrm{~h}$ )

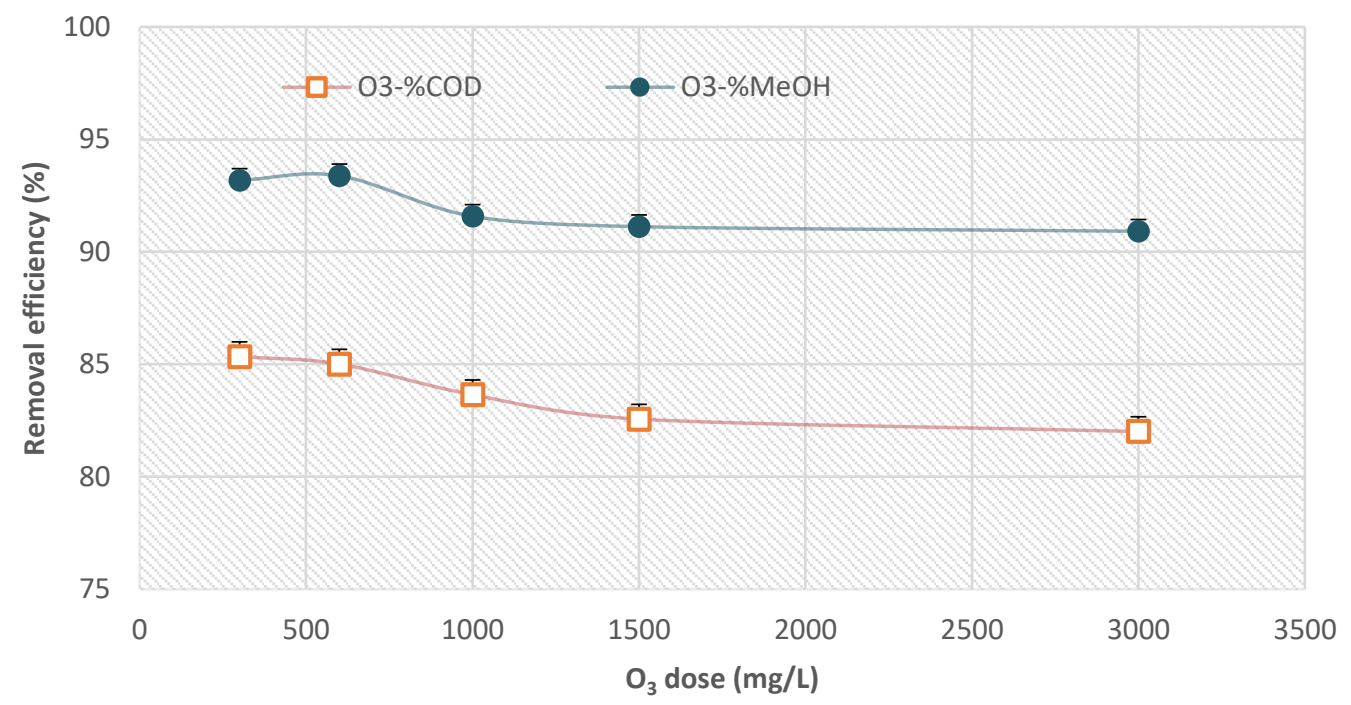

Figure 4. The effect of $\mathrm{O}_{3}$ dose on the $\mathrm{COD}$ and $\mathrm{MeOH}$ removal efficiency $\left(\mathrm{C}_{\mathrm{o}, \mathrm{COD}}=17200 \mathrm{mg} / \mathrm{L} ; \mathrm{C}_{\mathrm{o}, \mathrm{MeOH}}=\right.$ $6375 \mathrm{mg} / \mathrm{L} ; \mathrm{pH} 13 ; \mathrm{KMnO}_{4}$ dose $=2 \mathrm{~g} / \mathrm{L} ; \mathrm{t}=1 \mathrm{~h}$ ) 


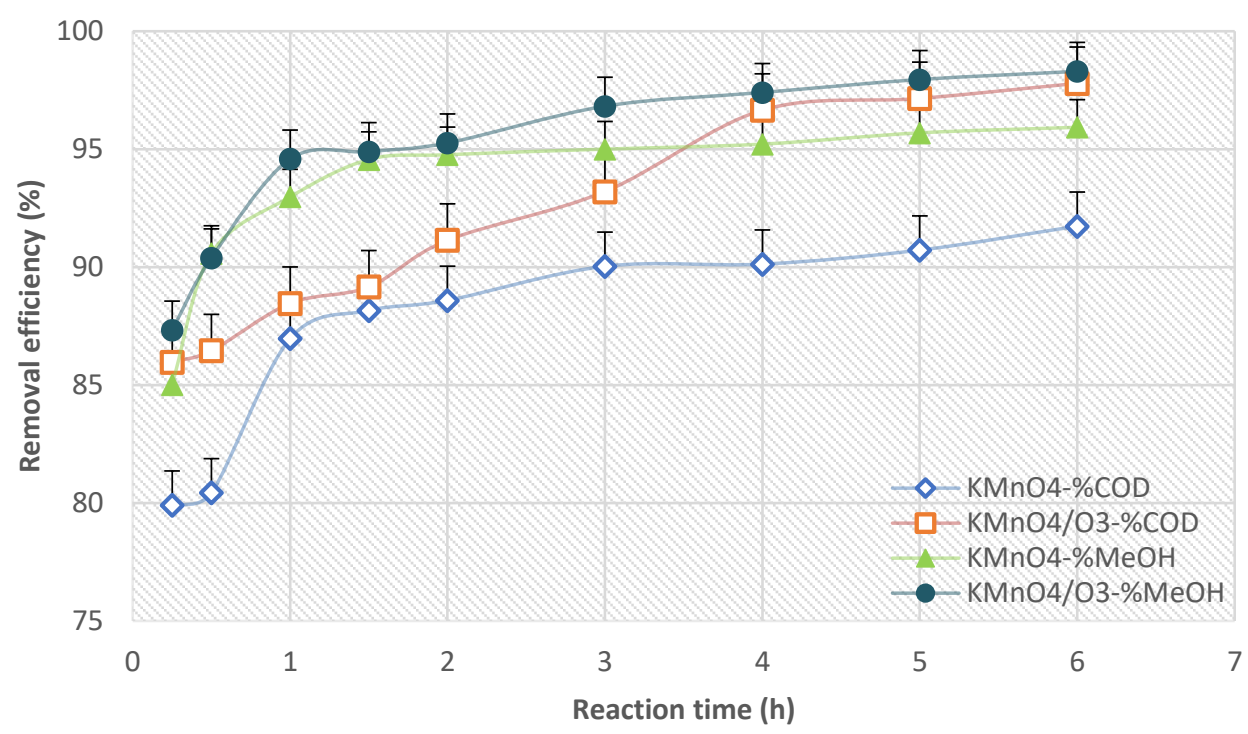

Figure 5. The effect of reaction time on the $\mathrm{COD}$ and $\mathrm{MeOH}$ removal efficiency $\left(\mathrm{C}_{\mathrm{o}, \mathrm{COD}}=17200 \mathrm{mg} / \mathrm{L} ; \mathrm{C}_{\mathrm{o}, \mathrm{MeOH}}=\right.$ $6375 \mathrm{mg} / \mathrm{L} ; \mathrm{pH}_{\mathrm{KMnO} 4} 2 ; \mathrm{pH}_{\mathrm{KMnO} 4 / \mathrm{O} 3} 13 ; \mathrm{KMnO}_{4}$ dose $_{\mathrm{KMnO} 4}=5 \mathrm{~g} / \mathrm{L} ; \mathrm{KMnO}_{4}$ dose $_{\mathrm{KMnO} 4 / \mathrm{O} 3} ; \mathrm{O}_{3}$ dose $=3000 \mathrm{mg} / \mathrm{L} ; \mathrm{t}=1$ h)
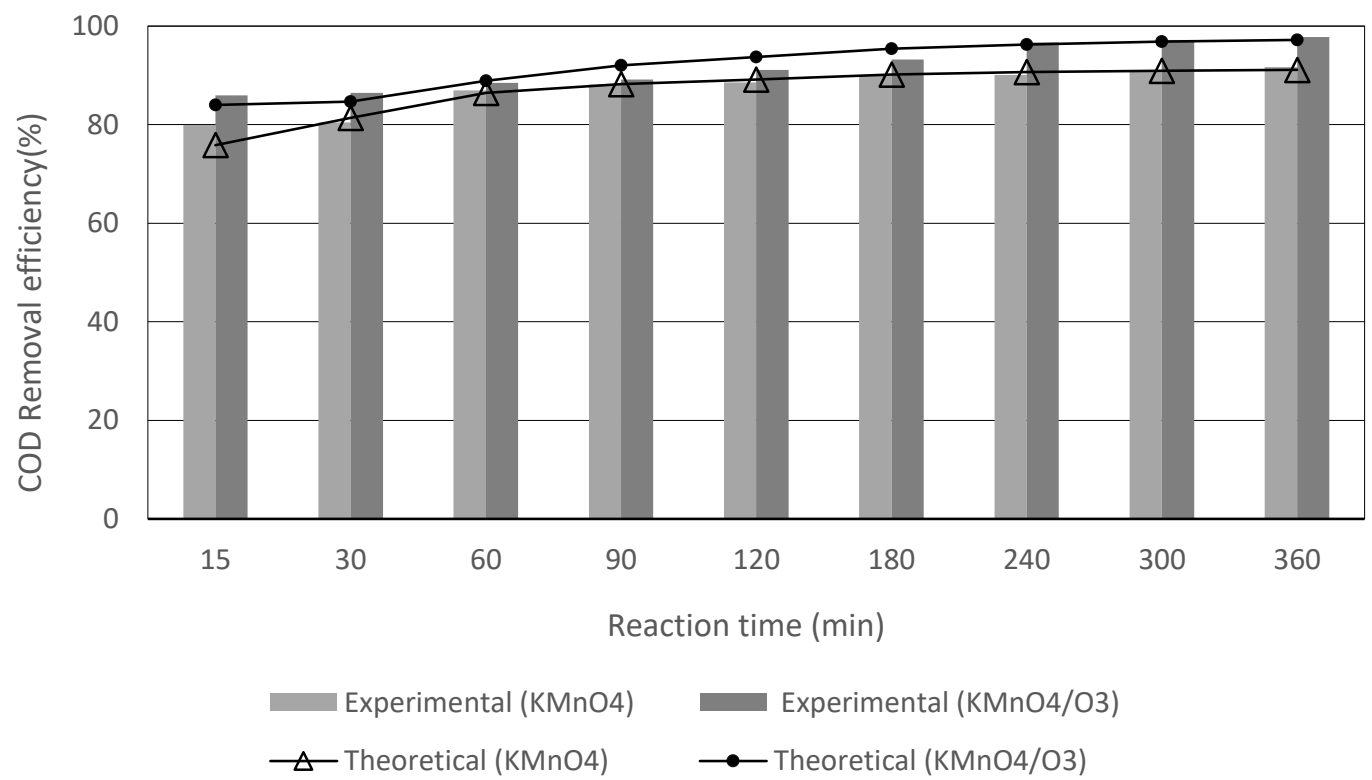

Figure 6. Theoretical and experimental COD removal efficiency as pseudo $2^{\text {nd }}$ order kinetics 


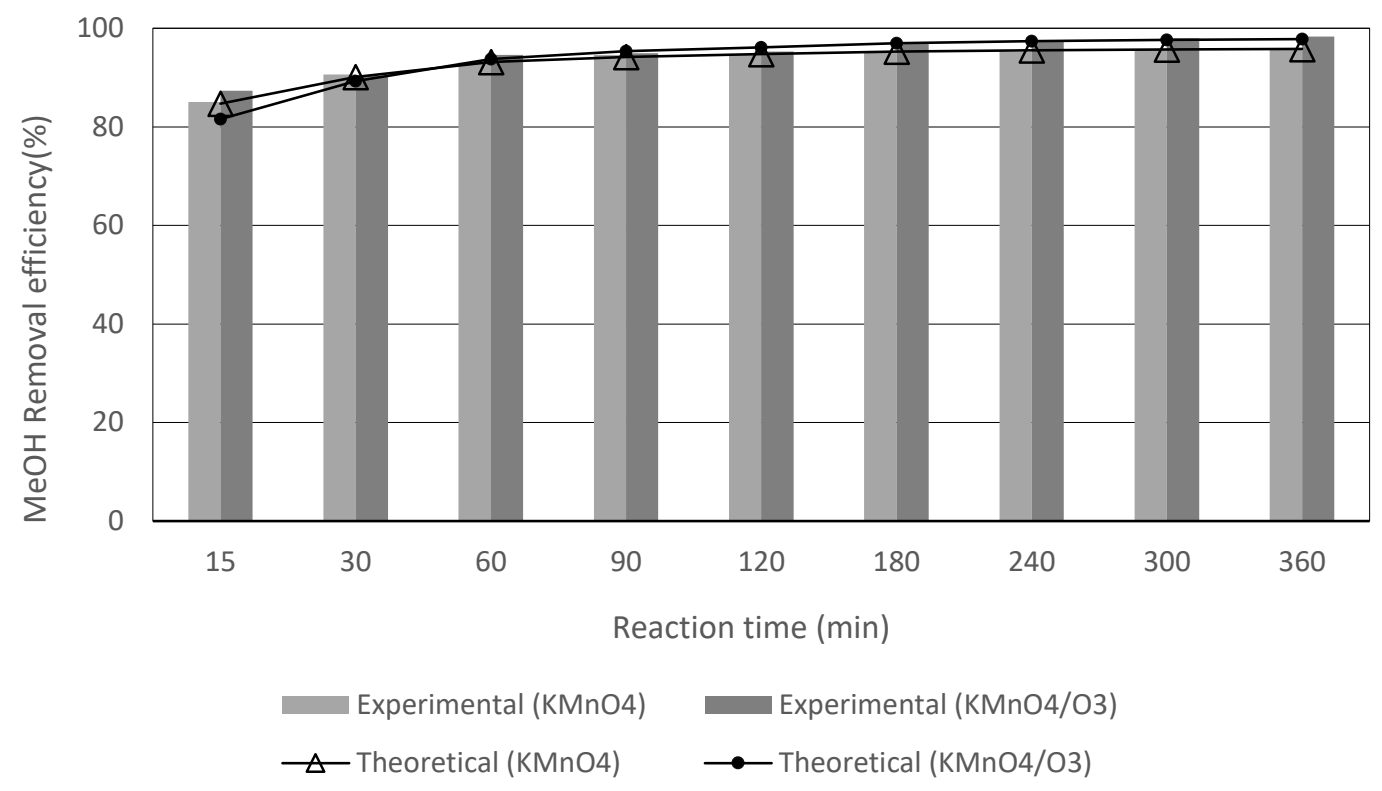

Figure 7. Theoretical and experimental $\mathrm{MeOH}$ removal efficiency as pseudo $2^{\text {nd }}$ order kinetics 